\title{
Generalized Building Energy Efficiency and New Energy Utilization
}

\author{
Li Yang ${ }^{1,2, *}$, Piman Sun $^{1,2}$ \\ ${ }^{1}$ College of Architecture and Urban Planning, Tongji University, Shanghai, P. R. China \\ ${ }^{2}$ Key Laboratory of Ecology and Energy Saving Study of Dense Habitat, Ministry of Education, Shanghai, P. R. China
}

\begin{abstract}
The development of human society is a non-stop gear, and the way we use energy is about the future. How to use resources reasonably and effectively is the pressure we face. The increase in population is the problem of resource allocation-insufficient inventory of traditional energy sources. Economic development is a double-sided blade, and ecological environmental protection is our focus. Research and development of new energy and renewable energy is a way to block dependence on traditional energy sources. It is the inevitable way for human beings to coexist harmoniously with ecology in the future. The development of the construction industry has also brought about a greater proportion of energy consumption. Building heating, ventilation, air conditioning and lighting account for about one-third of the total energy consumption. The carbon dioxide emissions of the construction industry account for more than half of the total emissions, which has a great impact on the environment. The broad definition of building energy conservation is proposed, and the significance of using new energy to building energy conservation is expanded from the perspective of macro environment, including the use of integrated energy, solar energy, and energy islands to achieve zero energy consumption in building energy conservation. The construction has effectively promoted the development of zero energy consumption in terms of the life cycle and environmental protection.
\end{abstract}

\section{Introduction}

Fast-Growing China has a massive demand for energy, especially oil and gas. Relying on imported energy has become a bottleneck restricting China's social economy. However, in the past, research on energy-saving methods has made significant progress, including materials, technology, etc. But in the aspects of architectural design, generalized energy saving strategy and application method is also restricted to passively circulating energysaving standards, it uses the building size coefficient, energy-saving windows, doors, and other means to make a rough response, lacking the development and application of systematic, comprehensive and all-around green energy-saving design means. Therefore, in the process of the construction planning and design, it is urgent to start from the macro perspective of overall energy efficiency, adjust the total energy consumption structure, improve the energy use efficiency, effectively develop and utilize new energy sources based on solar energy ${ }^{[1]}$. Building energy systems for the whole city with new renewable energy sources, will reduce carbon emissions, promote China's economic sustainable development, strengthen urban environmental protection and green building construction and promotion.

\section{Generalized building energy efficiency}

Generalized building energy efficiency is a whole building energy saving idea, proposed by this paper, from the macro perspective of the sustainable development of the environment, involves many aspects such as the overall environmental protection, building energy sustainable development mechanism, and the control of the whole energy concept to zero energy consumption construction $^{[2] \text {. }}$

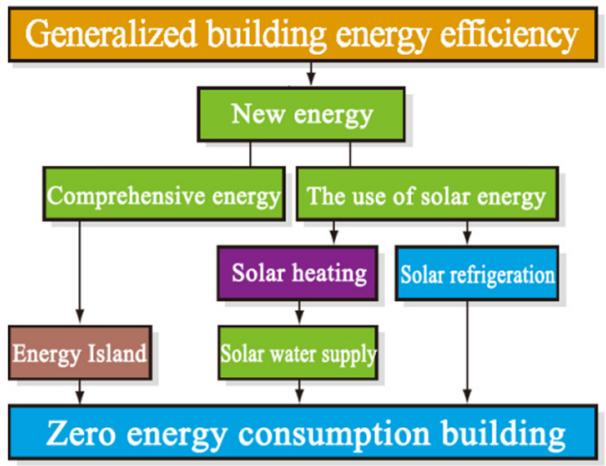

Fig.1 Generalized building energy efficiency and new energy system map. 
Generalized building energy efficiency in buildings is not limited to a building' $\mathrm{s}$ energy-saving measures, but a comprehensive zero energy building energy-saving design concept which is comprehensive energy; energy Island-distributed heating-cooling system, solar heating, solar energy water supply, solar refrigeration, and other systems act as one (Figure 1). In this paper, we put forward the theory and method of broadly-defined energy conservation in buildings and new energy utilization and comprehensively discuss the building energy saving method, aiming at the real green building.

\section{New energy sources}

The energy crisis has become a global problem. It has proven that in the number of energy sources that can be mined, the service life of coal is about 100 years, oil is 30 to 40 years, and natural gas is from 50 to 60 years. Today's construction industry is also facing the great challenge of the ecological crisis, the harmful substances produced by the burning of fossil fuels, construction, and industrial production has become the main factor of environmental pollution. It directly resulted in the growth of adverse problems such as climate change, greenhouse effect, desertification, and the decrease of species diversity; these deteriorations also led to serious damage to resource security and atmospheric environment, human survival environment has been threatened, so it is imperative to research and push for new green energy. ${ }^{[3]}$

With the reduction of energy, the economy has also been affected, excessive consumption of some nonrenewable resources led to the problem of shortage of earth's available energy or even exhaustion, and caused damage to the atmospheric environment. Due to the urgent need for new energy development and utilization, the research and development of new energy buildings will become a hot topic. This will become the focus of architectural development and environmental transformation in the next few years. It will be of great significance to China's economic development and social construction. ${ }^{[4]}$

New energy relative to conventional energy sources is a generalized and relative concept. New energy sources include the following: hydropower, bioenergy, wind, ocean, solar, geothermal, etc. ${ }^{[5]}$

\subsection{Energy island}

A distributed power supply system, compared to the traditional centralized power supply mode, sets the power system equipment near the user at a small scale (a few kilowatts-50MW small modular), a decentralized approach, which can output power, heat and cold energy independently. The way a distributed power supply system works includes an internal combustion engine, use of gas fuel or liquid fuel, micro gas turbine and a variety of fuel cells. Most of all, the distributed generation system has good environmental protection performance (Figure 2).

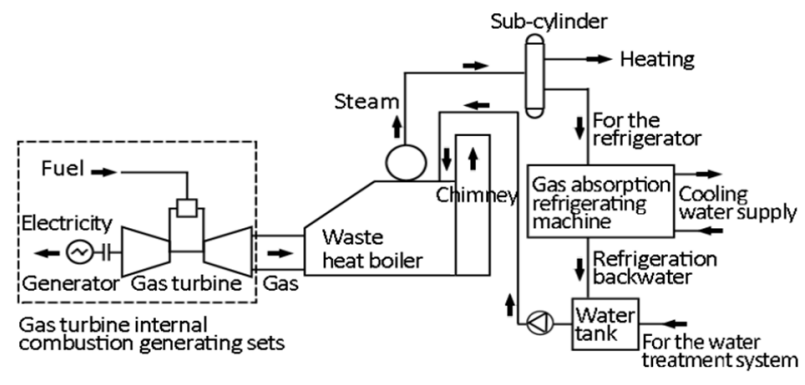

Fig.2 Energy island system.

Distributed power systems have some advantages over traditional centralized power stations, such as:

- It does not require the construction of a power station. It can reduce the transmission and distribution costs;

- It has the characteristics that transmission and distribution loss is very low or zero;

- It has a variety of thermoelectric ratio changes;

The installation cost and the construction cost is low;

- It can avoid large-scale power failure, each of the power supply systems is relatively independent;

- It can control regional power performance and quality detection conveniently and is more suitable to provide power for the countryside, mountains, development zones, residential areas, and commercial areas.

"Energy Island" also known as Combined Cooling Heating and Power(CCHP), which is a typically distributed power supply mode, has a linkage function system integrating the process of heat addition (heating and heating water) refrigeration and power generation. "Energy Island" can significantly improve energy efficiency: the average power generation efficiency of an ordinary power plant is generally $30 \%-50 \%$, while the "Energy Island" energy utilization rate can be as high as $90 \%$ without transmission loss, and can reduce harmful emissions. ${ }^{[6]}$ (Figure 3).

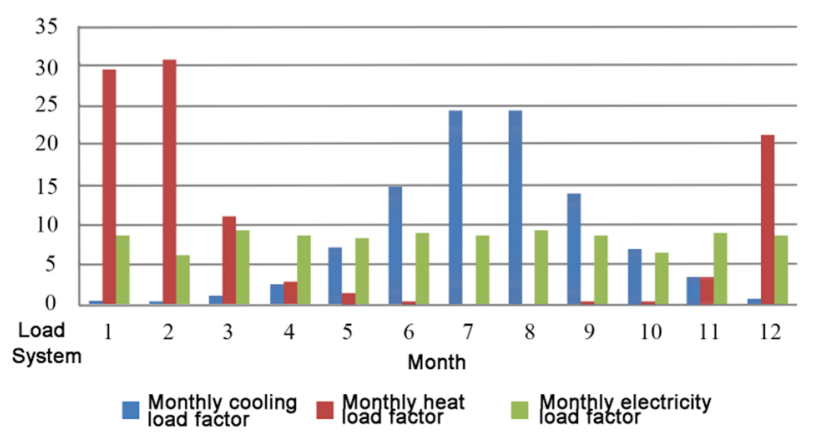

Fig.3 Monthly average air conditioning load chart.

\section{The use of solar energy}

Solar thermal technology and solar photovoltaic technology are the current development priorities. The extension of these technologies is the future trend. The solar energy-related technologies in architectural design include heating, water supply, and power supply.

Geography environments and climatic conditions around the buildings have a particular influence on solar energy. We should focus on the engineering situation to 
consider geographic features and climatic conditions, to take different Reasonably arrange each component in the solar system, which should be organically combined with building elements, and considered from the perspective of architectural aesthetics to design a new architectural model. When the efficient use of solar energy is available, architectural aesthetics is also necessary. Thus solar energy efficiency and building integration is the goal of the application and development of solar energy.

\subsection{Solar heating water}

Solar collectors, water tanks, circulation pumps, electric control cabinets, and water pipes form a solar water heating system ${ }^{[7]}$. This solar water heating system consists of four types of cycles:

- Constant cycle type (medium, large system),

- Water temperature discharge type,

- Forced circulation type (medium and large systems),

- Natural circulation type (small solar system).

In the process of solar water heating system design, we should give full consideration to the solar heat collector area, pipe material construction, hot water storage tank shape, circulating water inlet pipe and water outlet pipe diameter, water tank insulation materials, pipe insulation material, etc.

\subsection{Solar energy ventilation structure}

Solar ventilation structure is the organic combination of the exterior retaining structure of a building and its solar collector, making a retaining structure combined with ventilation structure, passive cooling, heating mode, to meet architectural aesthetics and to further improve the indoor thermal environment. The principle of Solar ventilation structure is to use hot pressing generated by solar radiation to cause the flow of air and then transform the collected heat energy into the kinetic energy of air flow. Solar thermal roof and solar heat collecting wall are the two main technological forms of solar ventilation structure. The use of solar radiant energy generates hot pressure under natural airflow, assisting in the use of ventilation to regulate the indoor temperature ${ }^{[8]}$.

\subsection{Solar refrigeration design}

Solar energy refrigeration has two types, solar thermal conversion refrigeration type, and solar photovoltaic conversion refrigeration type. The latter transforms solar energy collected into electrical energy and then uses the electric energy to drive the refrigeration machine to carry on the refrigeration. And the cost of solar cells is high when under the same cooling power, the cost of the solar photoelectric conversion refrigeration system is more than the cost of the solar thermal conversion refrigeration system, which also led to the difficulties in the promotion. Solar absorption refrigeration is through light and heat conversion refrigeration, which is a kind of system that cools down through the constant change in the concentration of the solution. It uses energy collected by solar collectors for water heating, providing the refrigerant generator with hot water so that the absorption refrigeration machine can operate normally to achieve the effect of refrigeration. Besides, there are solar energy, adsorption, vapor compression refrigeration systems and other light and heat conversion systems. Solar refrigeration designs should be based on local geography and climate, so geographical location and climatic environment directly affect solar refrigerator cooling capacity (Figure 4).

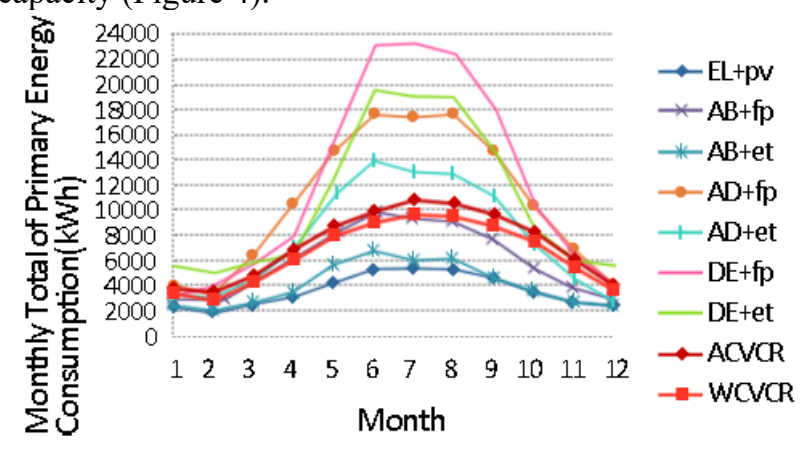

Fig. 4 Annual general situation of energy consumption and conventional power driven.

\section{Zero energy consumption building}

\subsection{Integrated design framework for zero energy residential building}

Finding problems that exist in the living environment is the first step to develop zero energy buildings, and consider people's demand in the living environment, according to all kinds of sustainable development technology, thus effectively improving the promotional value of zero energy buildings. Urban residential building is faced with a high population density, relatively traditional construction method, aging system equipment, much defective building physics performance and a lack of resources and other problems; these problems are particularly significant in large and medium-sized cities in China, so zero energy building design and integration of sustainable strategy will become a significant challenge. This paper, from zero energy consumption building design to the construction process, integrates sustainable strategy and its technical framework.

\subsection{Solution to the problem of building agings}

With the continuous development of the construction industry, a large number of urban construction will be faced with the problem of aging and timely updates, mainly including two aspects:

\subsubsection{Safety}

Due to old urban areas not affected by organic protection and renewal, traditional architecture needs maintenance; kitchen, toilet and other illegal temporary buildings added by old city residents bring the destruction of the old style and have huge security risks. 


\subsubsection{Urban aging}

Through years of large-scale rapid construction, urban construction technology and quality standards are gradually increasing, a large number of buildings are already facing a transformation of energy-saving, seismic structure, equipment updates, and other issues before reaching a full life cycle. There is a co-existence of opportunities and problems, construction and renewal. We should use reasonable urban construction update modes combined with characteristics of sustainable development technology to solve the problem of urban aging gradually.

\subsection{Integrated design of solar energy and building}

The two parts of active solar energy are the photovoltaic system and the light and heat system. The modular strategy requires the solar system to fit the two basic modules on the spatial scale. In the design, we must not only emphasize the energy utilization and conversion efficiency of the energy system itself but also emphasize the space-saving advantages of the solar system; which includes solar photovoltaic panels, controllers, solar energy panels, lines, etc. In the limited elevation and area of the roof, we must try to maximize the energy and achieve energy conversion.

\subsection{Passive energy-saving strategy in plan design}

Zero energy residential needs to achieve "open source" and "throttle" dual goals. Reasonable and organic architectural plan design will effectively reduce building energy consumption. As far as a building is concerned, it is as far as possible to build the highest building space in the best physical space environment, including bedrooms, living room and dining room, and then the storage room, kitchen, and toilet. The floor plan design is used to set the most comfortable and the relative core space in the best position, by using nested space from the inside to outside, packaging the core parts. The core space of the microenvironment will gradually transition from the inside to the outside, improving the thermal comfort of the human body in the indoor environment, while using passive strategies to save energy consumption.

\section{Conclusion}

Energy-efficient buildings should pay attention to energy conservation in design, and more importantly, reduce the long-term use of total energy consumption. The key method is to study the energy consumption structure and supply mode of buildings to improve energy efficiency during building use. There are also innovations such as heating systems and heating systems. Energy-efficient buildings cannot be limited to the type of building walls, the insulation of doors and windows. We should achieve the real purpose of saving energy by the method of broadly-defined energy conservation in buildings.
Specifics include the application of solar heating, water supply, refrigeration, use of energy islands, a distributed electro thermal cold-energy supply system, geothermal, building orientation, shading, the popularization of zero energy consumption and many other problems. Buildings consume much energy; at present, China's construction industry is developing rapidly; it is the inevitable trend in building development that energy-saving, green environmental protection, ecological technology in engineering must be applied.

\section{Acknowledgment}

This work was financially supported by the national science foundation of China . (No. 51378365)

\section{References}

1. L. Yang, Green building design: Wind environment of building (Tongji University Press, Shanghai, 2014)

2. L. Yang, X. D. Liu, F. Qian, J. Clean Prod. 209, 886$902(2019)$

3. W. J. Jiang, N. X. Ren, Build. Energy Conserv. 39, 31-35 (2011)

4. F. Qian, Appl. Mech. Mater, 737, 139-144 (2015)

5. F. Wang, Study on load characteristics of CCHP system driven by gas (Southeast University, Nanjing, 2009)

6. L. Yang, Green building design: Building energy efficiency (Tongji University Press, Shanghai, 2016)

7. L. Yang, B. J. He, M. Ye, Technol. in Society, 38, 111-118 (2014)

8. Y. Sun, Q. Wu, G. Shi, Energy Environ. Sci. 4, 1113-1132 (2011) 